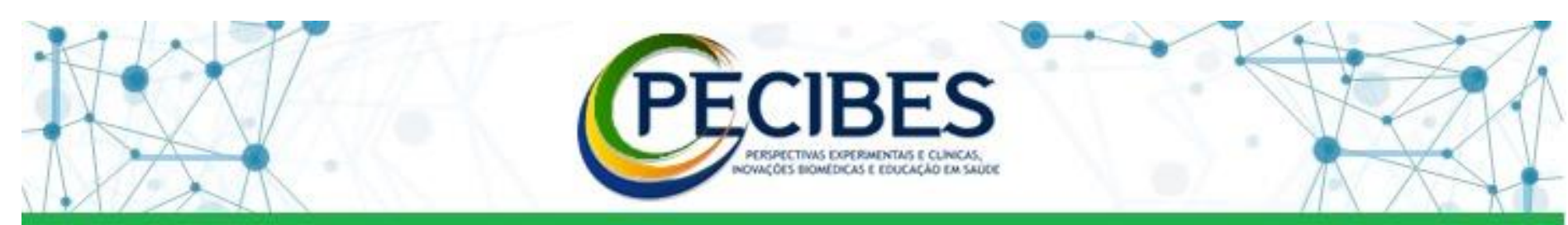

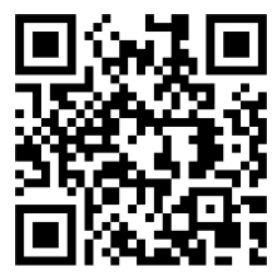

http://www.seer.ufms.br/ index.php/pecibes/index

\begin{abstract}
*Autor
correspondente:

Maurício Rodrigues

Comin, Universidade

Federal de Mato

Grosso do Sul - UFMS.

E-mail do

autor:mauriciorcomin

@icloud.com
\end{abstract}

Descritores:Exercício,

Hipertrofia de

Músculo

Esquelético,

Suplementação

Nutricional.

Key-words: COVID-

19.

Ultrasonography.Diap hragm.

Respiratory function

tests.

Palabras clave:

COVID-19.

Ultrassonografia.

Diafragma. Pruebas

de

funciónrespiratoria..

\section{Aspectos morfofuncionais diafragmáticos e função pulmonar em pacientes pós COVID-19 que foram submetidos a ventilação mecânica invasiva}

Diaphragmatic morphofunctional aspects and lung function in post-COVID-19 patients who underwent invasive mechanical ventilation

Maurício Rodrigues Comin ${ }^{1}$,Paulo Henrique Muleta Andrade², Marília Rodrigues Leite de Castro $^{3}$, Thamara Ferro Balsani Comin ${ }^{4}$, Talita Correia dos Santos ${ }^{5}$

1. Fisioterapeuta. Residente do Programa de Residência Multiprofissional em Reabilitação Física, Universidade Federal de Mato Grosso do Sul - UFMS/Brasil.

2. Fisioterapeuta. Pós-doutorando, Universidade Federal de Mato Grosso do Sul - UFMS, Campo Grande - Mato Grosso do Sul, Brasil.

3. Médica. Cardiologista do PROCARDIO - Hospital do Coração e do Centro Especializado em Reabilitação da Associação de Pais e Amigos dos Excepcionais de Campo Grande - Mato Grosso do Sul, Brasil

4. Fisioterapeuta - Mestranda, Universidade Federal de Mato Grosso do Sul - UFMS, Campo Grande- Mato Grosso do Sul, Brasil.

5. Graduanda, Centro Universitário UNIGRAN Capital, Campo Grande - Mato Grosso do Sul, Brasil.

Introdução: Os pacientes com COVID-19 comumente necessitam da utilização do suporte ventilatório por insuficiência respiratória aguda. Entretanto, a utilização de ventilação mecânica invasiva está relacionada a várias complicações. Além disso, há alta taxa de sequelas motoras, pulmonares, cardíacas e emocionais que ainda não estão bem esclarecidas na literatura. Objetivo: Avaliar e correlacionar os aspectos morfofuncionais diafragmáticos e função pulmonar de pacientes acometidos por COVID-19. Materiais e Métodos: Estudo transversal prospectivo que está sendo realizado no CER APAE de Campo Grande (MS), com aprovação do comitê de ética

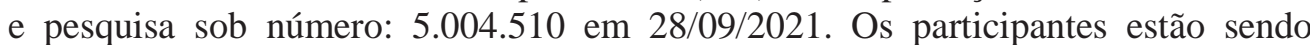
avaliados através do exame de ultrassonografia diafragmática, também é mensurada a capacidade vital lenta, a capacidade expiratória forçada e a capacidade expiratória forçada em 1 segundo, contemplando os exames de função pulmonar (ventilometria e espirometria). Para avaliação subjetiva da fadiga está sendo utilizado o pictograma de fadiga, com objeto de correlacionar esses achados com os dados de função pulmonar e morfofuncionalidade diafragmática. Os participantes ajustam-se em dois grupos, conforme o tempo de alta hospitalar: menor ou igual a três meses de alta (grupo A classificado como síndrome pós COVID-19 aguda) e maior do que três meses (grupo B classificado como síndrome pós COVID-19 crônica). Resultados e Conclusões parciais: foram avaliados quatro homens e trêsmulheres, com média de idade de $46 \pm 6,2$; quatro na fase aguda e três na fase crônica da síndrome pósCOVID-19. $75 \%$ da fase aguda apresentaram restrição severa na espirometria associada com a fração de espessamento do diafragma maior que $30 \% ; 50 \%$ participantes com espirometria normal apresentaram ainda sintomas de fadiga, cansaço e falta de ar leve. Apenas dois participantes (um da fase aguda e um da fase crônica) com testes de função respiratória normal, relataram ausência de sintomas e ainda ultrassonografia cinesiológica diafragmática sem alterações pertinentes. 